\title{
Hacia la reorganización del mecanismo de reciclaje financiero internaciona $1^{*}$
}

En el presente trabajo se analiza la naturaleza del endeudamiento externo en que han venido incurriendo los países en vías de desarrollo. Se propone la tesis de que el mecanismo de reciclaje de excedentes financieros no será la reproducción del que tuvo lugar en el período 1973-1982 y se examinan algunos de los elementos que deberán tenerse en cuenta en su eventual reorganización.

I. El praceso de ajuste y la aceleración del endeudamiento externo de los paises en vias de desarrollo

La crisis que afecta a la economía internacional desde 1.973 ha sido debatida "in extenso" en la prensa y la literatura especializada, razón por la cual no nos detendremos a analizar ni sus orígenes ni su evolución.

En cambio, nos limitaremos a registrar tres de sus efectos que, a nuestro juicio son indispensables para el examen del proceso de reciclaje financiero que nos interesa, a saber:

a) El proteccionismo comercial se ha generalizado y el volumen del comercio mundial se ha estancadot;

b) La amenazante combinación inflación-desempleo-estancamiento económico no ha podido ser efectivamente combatida mediante el uso de los instrumentos tradicionales de la política económica;

c) Los significativos intereses de grupo perseguidos con tenacidad por los países industrializados y los países exportadores de pe: tróleo, respectivamente, no han podido ser alcanzados mediante la adopción de estrategias unilaterales. En efecto, ni el abastecimiento seguro de petróleo, a precios concertados, objetivo prioritario de

* Este documento fue presentado en el Simposio sobre el Mercado Financiero Internacional, Rio de Janeiro, diciembre 1982.

'El valor de las exportaciones globales aumentó sólo en uno por ciento en 1980 y se mantuvo estacionario en 1981, año en el cual las exportaciones de petróleo se redujeron en un 14 por ciento, $y$ las de materias primas minerales en un 5 por ciento. Ref. I. 
los primeros, ni la mantención del poder adquisitivo del precio del petróleo, aspiración de los segundos, han podido ser logrados en medio del clima políticamente beligerante y económicamente recesivo predominante desde 1973.

Entretanto, los países en vías de desarrollo han asistido a un constante deterioro tanto de sus términos de intercambio comercial cuanto de su situación de pagos externos y, como consecuencia, a una creciente limitación de sus posibilidades de desarrollo socioeconómico.

Sobre el caso más específico de los países latinoamericanos, cabe señalar que su desarrollo se debilitó considerablemente entre 1975 y 1980: la tasa media de crecimiento anual del producto regional se redujo a 4,6 por ciento y la de inversión a solamente un 3,8 por ciento. En 1981, la declinación del crecimiento económico de América Latina se acentuó, registrándose un incremento del producto agregado de la región de menos del uno por ciento, vale decir, la tasa de crecimiento más baja en los últimos treinta años. Entre los factores que-se conjugaron para provocar el mencionado deterioro cabe mencionar las alzas extraordinarias del precio del petróleo y de las tasas de interés, y las fuertes fluctuaciones experimentadas por los volúmenes y los precios unitarios de las exportaciones. Lo anterior, unido al aumento sostenido de las importaciones, condujo a un agudo empeoramiento del défict corriente de la balanza de pagos en la mayoría de estos países. EI déficit externo, que creció en valores absolutos de 7.100 millones de dólares en 1974 a 27.400 millones de dólares en 1980, también aumentó con relación al producto nacional, de una proporción de 3 por ciento en 1971-74 a cerca de 7 por ciento en $1980^{2}$. 'Como consecuencia, la región en su conjunto debió recurrir a una vigorosa movilización de recursos financieros externos para poder hacer frente al déficit indicado. La inversión privada directa extranjera, que tradicionalmente ha sido un rubro importante en los ingresos de capital de América Latina, registró una tendencia general ascendente durante estos años, pero dado que su incremento resultó bastante menor que el de las necesidades financieras de la región, su aporte al financiamiento externo global disminuyó de un 30 por ciento en los años sesenta a sólo un 17 por ciento en 1976-80. Por lo tanto, una proporción creciente de la movilización total de recursos estuvo constituida por préstamos de diversos tipos, lo que provocó un rápido crecimiento del endeudamiento externo.

La deuda externa total de Ios países latinoamericanos vigente a fines de 1980 ha sido estimada en una cifra de alrededor de 200.000 millones de dólares. De esta suma, la parte constituida por la deuda pública, inclusive las obligaciones financieras externas de enti-

Ref. 2, p. 17. 
dades privadas que tienen la garantfa oficial, ascendió a 161.000: millones de dólares. La expansión de là deuda pública externa de los países latinoamericanos, calculada sobre la base de doblares de poder adquisitivo constante, se aceleró de una tasa media de 9 por ciento en 1961-72 a 15 por ciento en 1973-79. Para la región en su conjunto, la deuda como proporción del producto aumentó de un promedio de 13,5 por ciento en la década de los sesenta a alrededor de 33 por ciento en 1978-80. Para el grupo de los países de menor desarrollo económico relativo de América Latina, esa proporción aumentó de 16 por ciento a 45 por ciento entre los dos períodos considerados ${ }^{3}$.

En lo que va transcurrido del presente año (1982), la situación de endeudamiento y de pagos externos de la mayoría de los países en vías de desarrollo se ha deteriorado considerablemente y ha sido frecuente escuchar u oler comentarios de observatorios ortodoxos que, no sin cierta frivolidad, preconizan que dichos países estarían gastando "por encima de sus posibilidades", que estarían gastando "demasiado".

A nuestro juicio, en vez de tratar de respondernos a la pregunta: ¿cuánto es "demasiado"?, estimamos más constructivo reflexionar sobre el destino del gasto financiado con la deuda externa. Si éste se destina a aumentar el consumo de bienes suntuarios o superfluos, o bien a hacerse de una posición desproporcionada de reservas internacionales, quizás habría lugar para juicios de valor como el indicado; pero si contribuye al esfuerzo que los países están haciendo para llevar a cabo sus impostergables programas de inversión social y productiva, esa clase de opiniones no parece tener mucha justificación.

Examinemos, a manera de ejemplo, el caso del Brasil: con una población de 120 millones de habitantes, que crece en torno del 3 por ciento anual, la economía nacional tiene que crecer sostenidamente no menos del 6 por ciento anual, como promedio, para poder dar empleo a 1.5 millones de personas que requieren incorporarse al mercado de trabajo cada año. Ahora bien, ca cuánto asciende la inversión productiva que se requiere efectuar anualmente para satisfacer este requerimiento? ¿Cuánto representa la inversión social que es preciso llevar a cabo para aumentar la oferta de servicios indispensables, tales como educación, salud, transporte urbano, agua potable, y comunicaciones? Esa inversión es cuantiosa y estimamos "grosso modo" que debe representar no menos del 25 o 30 por ciento del producto bruto interno ${ }^{4}$ Dadas las cifras absolutas y per cápita del ingreso, y la necesariamente alta propensión

iRef. 2, p. 18.

'Esta estimación sólo considera la inversión que sería necesaria para atender las necesidades derivadas del crecimiento vegetativo de la población, pero no la requerida para eliminar los déficit acumulados de servicios sociales. 
a su consumo, no cabe sino confirmar la urgente necesidad que tiene el país de recurrir al financiamiento externo para complementar al ahorro interno en la formación del capital productivo y social.

\section{Participación de la banca privada internacional en el mecanismo de reciclaje: Consecuencias.}

Al iniciarse el proceso de ajuste de la economía internacional, la única alternativa frente al endeudamiento externo que realmente tenían los países en vías de desarrollo era la de reducir sus niveles de consumo y de inversión productiva, limitar las importaciones y tratar, así, de equilibrar sus balanzas de pagos. Dado que esa opción significaba sacrificar sus posibilidades de crecimiento económico y mejoramiento social, un número significativo de esos países prefirió recurrir a la opción del endeudamiento, mediante la obtención de créditos junto a la banca privada internacional, principalmente en el mercado de eurodivisas.

Cabe aquí preguntarse cuáles fueron las causas de esa marcada preferencia. La evidencia parece indicar que la flexibilidad de esa clase de financiamientos, el carácter no condicionado de los créditos y la disponibilidad rápida de los recursos (en especial, para el fortalecimiento inmediato de la posición de reservas internacionales), fueron las principales ventajas que percibieron los países en vías de desarrollo.

Como consecuencia de esa percepción de "facilidad de acceso" a dichas fuentes, los países en vías de desarrollo han venido recurriendo a bancos privados para satisfacer una amplia variedad de propósitos, entre los cuales podemos mencionar el financiamiento de déficit de balanzas de pagos, el aumento de la posición de reservas internacionales, y el financiamiento de programas de inversión en infraestructura social y económica, para los cuales no les ha sido posible obtener ayruda externa oficial.

Entre las dificultades y los costos que frecuentemente invocan aquellos que consideran las operaciones contratadas con los bancos internacionales (dentro o fuera del mercado de eurodivisas) como poco adecuadas para financiar necesidades de inversión fija o déficit de balanzas de pagos de los países en vías de desarrollo, podemos mencionar las siguientes: la concentración de los pagos de amortización e intereses en períodos de tiempo normalmente inferiores a ocho años, la variabilidad de la tasa de interés aplicada, y la inestabilidad del mercado (riesgo de no otorgamiento de nuevos créditos, incluso para operaciones de roll-over en la eventualidad de que las perspectivas económicas del país deudor se vuelvan desfavorables.

Quizás sea oportuno en este contexto recordar que, no obstante el notable desarrollo y la eficiencia técnica demostrada por el mer- 
cado de eurodivisas y por la banca privada en el reciente reciclaje de recursos, esas instituciones no disponen aún de mecanismos que aseguren estabilidad a la distribución de los excedentes financieros internacionales, ni parecen atribuir suficiente prioridad al requisito de que los términos y condiciones de sus operaciones se adapten a las necesidades de financiamiento externo de los países en vías de desarrollo5.

Teniendo en mente las consideraciones anteriores, pasemos a examinar la magnitud y naturaleza de la responsabilidad asumida por la banca privada internacional al convertirse en el instrumento principal del mecanismo de reciclaje financiero mundial.

Hasta 1973, más del 54 por ciento de las necesidades de financiamiento externo (suma del déficit corriente de la balanza de pagos más el aumento de las reservas monecarias internacionales) de loṣ países en vías de desarrollo era cubierta por la ayuda oficial, tanto bilateral como multilateral. La inversión directa y los bancos privados financiaban el saldo de dichas necesidades ${ }^{6}$. Posteriormente, cuando éstas comenzaron a aumentar como consecuencia del alza sostenida de los precios del petróleo, los bancos privados internacionales comenzaron a incrementar significativamente su participación relativa en el financiamiento de las mismas. Otorgaron, como ya hemos comentado, masivos créditos en divisas a los paises deficitarios con cargo a los depósitos de los excedentes financieros que, a su vez, provenian fundamentalmente de los paises exportadores de petróleo.

Así fue como en 1979, los bancos privados llegaron a financiar casi el 50 por ciento de las referidas necesidades, en tanto que la inversión directa financiaba menos del 12 por ciento y las fuentes oficiales disminuían su participación a alrededor del 38 por ciento ${ }^{\top}$.

De esa manera, la proporción de la deuda externa total de los países en vías de desarrollo y de los países del Este detentada por la banca privada internacional creció desde 45 por cientó en 1972 a 65 por ciento en $1982^{\circ}$. La proporción de la deuda externa de los países en vías de desarrollo detentada por acreedores oficiales, tanto bilaterales como multilaterales, se redujo en forma concomitante, hasta llegar a representar alrededor del 35 por ciento en 1982.

Como hemos visto, la composición de la deuda de los países en vías de desarrollo por tipo de acreedores sufrió una transformación radical entre 1973 y 1982. Entretanto, la deuda externa de los países de mayor desarrollo relativo de América Latina experimentaba

'Al respecto ver Ref. 2., p. 13.

Ref. 3., p. 32, tabla 11.

Ref. 3., p. 32, tabla 11.

sproporción que representa 327 mil millones de dólares. Ver Ref. 4 Business Week, September 6, 1982. "Worry at the WorId's Banks". 
una modificación similar. Sólo en los países de menor desarrollo relativo de la región, la proporción de las obligaciones con acreedores oficiales se mantuvo estable en torno del 58 por ciento del total9.

Como consecuencia de la participación creciente de los créditos contratados por los países latinoamericanos con bancos internacionales privados, los períodos de vencimiento y las tasas de interés de la deuda externa tendieron a deteriorarse a contar de 1973.

La tasa media de interés de la deuda contratada por dichos países se elevó de alrededor de 7 por ciento en 1970 a 11 por ciento en 198010, aproximándose así al tipo de interés practicado en el mercado del eurodólar, que a su vez se había incrementado de 6,9 por ciento a 11,7 por ciento en el período señalado. Las pequeñas diferencias entre ambas tasas deben atribuirse a la influencia de los menores tipos de interés de los créditos oficiales recibidos por los diversos países de la región. Simultáneamente, y por la misma razón, el plazo medio de amortización de los créditos contratados se redujo de 13 a 9,4 años entre 1970 y $1980^{11}$.

Como efecto inevitable de los hechos expuestos, la carga constituida por el pago de los intereses y las amortizaciones de la deuda pública externa pasó a representar una proporción creciente del valor de las exportaciones latinoamericanas, que se elevó desde 13 por ciento a más de 28 por ciento entre 1974 y $1980^{12}$. Dicho efecto, junto con el debilitamiento del comercio internacional y el correspondiente deterioro de los términos de intercambio de las economias latinoamericanas, ha contribuido a limitar severamente la capacidad de éstas para financiar sus inversiones productivas en condiciones adecuadas de costo financiero y de plazo de vencimiento.

Como veremos a continuación, la combinación de los deterioros en las cuentas comercial y corriente de la balanza de pagos de los países en vías de desarrollo se ha vuelto de tal manera adversa, que ha comprometido el propio funcionamiento del mecanismo de reciclaje de los excedentes financieros internacionales ${ }^{18}$.

'Ref. 2., p. 19.

${ }^{10}$ Como referencia, cabe indicar que el Indice de inflación de los pafses de la OCDE, al cual se alude cuando se habla incorrectamente de "la tasa de infla. ciśn mundial", se elevó del 5,2 por ciento al 10,2 por ciento en el mismo período.

"Ref. 2., pp. 19 y 20.

12Ref. 2., p. 20.

${ }^{13} \mathrm{El}$ déficit corriente agregado de balanza de pagos de los paises en vías de desarrollo se elevó de 11.500 a más de 100.000 millones de dólares (valor estimado) entre 1974 y 1982, representando aproximadamente 1,8 por ciento y 5 por ciento del correspondiente producto bruto agregado, respectivamente. En los paises de América Latina el respectivo déficit se elevó de 7.100 a 27.400 millones de dólares entre 1974 y 1980, cifras que representan aproximadamente el 3 por ciento y el 7 por ciento del producto agregado regional, respectivamente. Ver al respecto Ref. 2., pp. 9 y 17; y Ref. 3., p. 32. 


\section{Perspectivas del reciclaje financiero}

Diversas razones nos inducen a pensar que no será posible reproducir en los próximos años un proceso de reciclaje similar al que tuvo lugar entre 1973 y 1982. A nuestro juicio éste no podrá ser llevado a cabo en condiciones tan escasamente restrictivas, como en el pasado, ni tampoco teniendo a la banca privada internacional como principal instrumento.

En efecto, dicha posibilidad no parece, en primer término, compatible con la magnitud ni con el perfil de la deuda externa de la mayoría de los países en vías de desarrollo, ni tampoco con sus necesidades de ajuste estructural y de desarrollo socio-económico.

Tampoco parece favorecer dicha posibilidad el hecho de que la deuda está fuertemente concentrada en un número relativamente reducido de prestatarios, así como de bancos privados. En efecto, la aplicación más estricta de los límites de crédito por paíst4 por parte de Ios accionistas cle los bancos, sin duda va a contribuir a limitar la expansión de las obligaciones de los países que muestran un más alto endeudamiento global15.

Otra restricción que apunta en el mismo sentido es la probable disminución de la liquidez mundial en los próximos años, como consecuencia de la tendencia decreciente que muestran los superávit financieros de los países exportadores de petróleo ${ }^{16}$. Esta liquidez sólo podría aumentar en la segunda mitad del presente decenio si, como resultado de una eventual recuperación de la economía internacional, volviera a crecer fuertemente la demanda por petróleo, haciendo posible el alza anual de su precio internacional por sobre el índice de inflación de los países de la OCDE. Aún así, estimamos que esa eventual alza no podrá ser brusca, sino gradual, dado el firme avance que han tenido los procesos de conservación y de sustitución en el sector energético de esos mismos países. Solamente la improbable evolución de la economía internacional hacia condiciones de "boom"17 podría provocar tasas anuales de elevación del precio del petróleo que superasen sustancialmente el citado índice de inflación.

${ }^{I 4}$ Criterio de "country ceiling" aplicado por los bancos privados al monto de sus créditos con un país dado.

${ }^{15} \mathrm{La}$ banca privada probablemente va a concentrarse en operaciones de "rollover" de la deuda de dichos países.

${ }^{10} \mathrm{Ha}$ sido estimado que dicho superávit, que alcanzó su máximo valor, 112.000 millones de dólares, en 1980, descenderá a un valor estimado en 25.000 millones de dólares, en 1982. Ver Ref. 2, p. 8.

"Entendemos por "boom" económico aquella frase de prosperidad económica, caracterizada por elcradas tasas de crecimiento económico y alza generalizada de los precios de las materias primas, tal como la que prevaleció durante los años inmediatamente anteriores. a 1973. 
Una restricción adicional podría ser la eventual aplicación de normas de control más estrictas sobre las operaciones y reservas internacionales de sus bancos privados por parte de las autoridades monetarias de los países de la $O C D E^{18}$.

De acuerdo a los antecedentes examinados, parece necesario formular y evaluar, a la mayor brevedad, diversas hipótesis de reorganización del mecanismo de reciclaje que contemplen su mejor adaptación a las restricciones enunciadas, que entendemos prevalecerán durante la mayor parte de lo que resta del actual decenio. A nuestro juicio, la eventual reorganización, que no será probablemente explícita ${ }^{19}$, deberá satisfacer al menos dos condiciones, ciertamente dependientes una de la otra.

La primera condición es que el reciclaje deberá adecuarse a la dualidad del requerimiento de financiamiento externo de los países en vfas de desarrollo. En efecto, por una parte, conjugado con determinadas políticas de ajuste, deberá permitir a los países superar efectivamente sus transitorios déficit de balanza de pagos. Por la otra parte, deberá transferir suficientes recursos reales en términos y condiciones que hagan posible que dichos países puedan reiniciar su proceso de desarrollo económico, hoy virtualmente paralizado, y recuperar su status permanente de socios activos en el comercio mundial.

La segunda condición responde a la necesidad de operacionalizar la atención simultánea de ambos requisitos enunciados, para lo cual el mecanismo de reciclaje deberá permitir una participación marcadamente más equilibrada entre las diversas fuentes de financiamiento, a saber, entre los organismos multilaterales de financiamiento ${ }^{20}$, los gobiernos e instituciones oficiales de ayuda pública externa ${ }^{21}$, y los bancos privados internacionales.

En lo que sigue, examinaremos cuáles pueden ser las formas concretas de reorganización que podría asumir el mecanismo de reciclaje, de acuerdo con las hipótesis y requisitos adoptados.

En primer término, estimamos probable que las organizaciones multilaterales sean llamadas a participar mucho más activamente que en el pasado en el mecanismo de reciclaje que tendrá Iugar en los próximos años. Entre las razones que así nos inducen a creerlo, podemos mencionar:

I8Vex al respecto Ref. 4.

${ }^{10} \mathrm{Vale}$ decir, que tendrá mayores posibilidades de ser puesta en práctica mediante un cierto número de acciones parciales, aparentemente no concertadas, más bien que como resultado explícito de un consenso alcanzado en una o más reuniones internacionales de carácter oficial.

${ }^{20} \mathrm{El}$ Fondo Monetario Internacional, para concesión de créditos compensatorios de apoyo a la balanza de pagos, y el Banco Mundial, el BID y los demás bancos regionales y subregionales de fomento, para financiamiento de proyectos de desarrollo.

alFuentes denominadas genéricamente de "bilaterales", dado que dan origen a transacciones financieras entre dos gobiernos. 
Hernán Lafourcade ; Hacia la reorganización del mecanismo de reciclaje...

a) la racionalidad técnica y económica con que adoptan sus decisiones sobre ayuda financiera, que contrasta con el predominio de factores políticos que condiciona generalmente a la ayuda bilateral;

b) la preocupación por el uso efíciente de los recursos productivos que garantiza al país recipiente el retorno de la inversión y la contribución a la búsqueda de los equilibrios macroeconómicos internos (estabilidad del nivel de precios y pleno empleo) y externos (equilibrios comercial y de la balanza de pagos), en contraste con la menor prioridad relativa que normalmente se otorga a estos aspectos en los financiamientos comerciales privados;

c) la posibilidad de atraer recursos adicionales de origen priva: do para el financiamiento del desarrollo, mediante la garantía que ofrecen sus estudios de factibilidad del proyecto y su capacidad para combinarlos con recursos propios de origen multilateral;

d) la posibilidad de "armar" paquetes significativos de recursos financieros y tecnológicos para viabilizar grandes proyectos rentables en países económicamente débiles.

Desde que se inició el proceso de ajuste de la economía internacional los organismos multilaterales de financiamiento vienen adoptando una serie de medidas para aumentar su participación en el financiamiento de la ayuda oficial para el desarrollo ${ }^{22}$, a saber:

a) han disminuido su liquidez, aumentando la relación entre préstamos comprometidos y recursos clisponibles;

b) han gestionado ante sus países miembros la urgencia de aumentar tanto su capital pagado disponible para préstamos, como su capital no pagado, que sirve como garantía de sus emisiones de bonos en los mercados de capital;

c) han intensificado su actividad de captación de recursos en los mercados internacionales de capital;

d) han intensificado su función de intermediario financiero movilizando recursos de bancos privados para el financiamiento de proyectos de desarrollo.

En relación con esta última función, que puede ser ilustrada por el programa de financiamiento complementario adoptado por el BID en $1975^{23}$, señalemos de pasada que es posible que esté caracterizado un cambio cualitativo de importancia en el sistema de financiamiento externo para el desarrollo. Hasta hace poco tiempo, la banca privada y las agencias multilaterales operaban en escenarios virtualmente separados, con muy escasa relación mutua. Hoy, están haciendo esfuerzos para concertar sus actividades a través de mecanismos más flexibles, que procuran una complementación cada

${ }^{23}$ Con exclusión del FMI, cuya función es diferente.

${ }^{23} \mathrm{E} l$ Banco Mundial adoptó un programa similar en la misma época. 
vez mayor entre diversos tipos de financiamientos oficiales y comer. ciales para proyectos de desarrollo económico y social.

En segundo lugar, estimamos que la función de reciclaje que desempeñarán los bancos privados internacionales hacia los países en vías de desarrollo deberá poner más énfasis en los préstamos destinados al financiamiento de proyectos específicos, en contraste con la preferencia que han venido mostrando en los últimos años de otorgar créditos para propósitos generales, de apoyo a la balanza de pagos y de acumulación de reservas. Para hacer más efectiva su acción, deberán colaborar en forma más frecuente y estrecha con las instituciones financieras multilaterales en operaciones de financiamiento complementario ${ }^{24}$.

Es posible que los bancos privados también consideren entrar en acuerdos con el Fondo Monetario Internacional para llevar a cabo operaciones ..."conjugadas" de apoyo a la balanza de pagos de los países que recurran a dicha institución ${ }^{25}$.

Otro aspecto al cual los bancos deberán dar atención, es a la po. sibilidad de extender razonablemente los plazos de vencimiento de los préstamos para evitar así el riesgo derivado de la concentración de pagos, que tan adversamente está afectando a la comunidlad financiera internacional. En el caso del financiamiento de proyectos de inversión, los vencimientos deberán compatibilizarse con los requerimientos del flujo de caja de los mismos.

Los bancos deberán estar preparados para efectuar tareas "completas" en el mecanismo de reciclaje, escogiendo con mayor selectividad sus clientes y sus operaciones, de modo de no tener que procurar seguridad en el abandono del prestatario cuando comienzan las dificultades. Para ello, deberán utilizar más las informaciones técnicas, los estudios sobre comercio exterior y capacidad de pagos de los deudores, y los mecanismos de garantías, que eventualmente podrían poner a su disposición las instituciones multilaterales de financiamiento.

En tercer lugar, Ios propios gobiernos de los países en vías de desarrollo deberán sin duda alguna adoptar políticas destinadas a administrar más racionalmente la contratación de nueva deuda externa. Dichas políticas debieran contener, como mínimo, los siguientes elementos: a) contratación de deudas para financiar de preferencia, inversiones destinadas a aumentar la capacidad de producción de la economía y especialmente el desarrollo de los recursos naturales y el potencial de exportación. No hay mejor test de una política de endeudamiento externo que la verificación del empleo adecuado que se hace internamente de los recursos obtenidos; b) para propósitos de apoyo a la balanza de pagos, contratación de deudas que no presenten vencimientos concentrados en períodos dema-

"También conocidas como operaciones de "co-financiamiento".

${ }^{25}$ Ver al respecto Ref. 4. 
siado cortos de tiempo; c) administración de la deuda externa en permanente consulta informal con el Fondo Monetario Internacional.

No cabe poner término a estas reflexiones sobre las formas concretas que deberá asumir el mecanismo de reciclaje sin antes recordar que los gobiernos de los países de la ocDe, así como de los países exportadores de petróleo, deberán hacer todo lo que esté a su alcance para dotar oportunamente de recursos financieros suficientes a los organismos multilaterales de financiamiento (incluso al FMI) permitiendo que éstos queden efectivamente en condiciones de desempeñar las funciones identificadas anteriormente.

Un requisito que parece sine qua non para que el programa de ajuste tenga éxito y el reciclaje pueda llevarse a cabo en forma adecuada, es la promoción, por todos los países, y especialmente por Ios de la OCDE, del libre comercio y del combate al proteccionismo. Si este aspecto llegase a fallar, el resto de las medidas de reorganización y ajuste carecería de coherencia ${ }^{26}$.

\section{Conclustones}

La evidencia examinada en este trabajo indica que existen escasas posibilidades de que la banca privada internacional pueda constituirse, como en los últimos diez años, en el principal instrumento de reciclaje de los excedentes financieros internacionales. Sin duda los bancos privados continuarán desempeñando una función significativa en el financiamiento de las necesidades de recursos externos de los países en vías de desarrollo, pero estarán sujetos a un conjunto de restricciones técnicas y operacionales impuesto por sus propias autoridades monetarias y juntas de accionistas, así como por la obvia necesidad de adecuar los términos y condiciones de sus créditos a los requerimientos de la balanza de pagos y del desarrollo económico y social de esos países.

Es posible que en los próximos años asistamos a un proceso de reciclaje que, a diferencia del que tuvo lugar desde 1973 a esta parte, tomará en cuenta la señalada dualidad del requerimiento de financiamiento externo de los países en vías de desarrollo27. Para ello será necesario fortalecer la dotación de recursos de los organismos financieros multilaterales, y estimular la ejecución de operaciones "conjugadas" entre el Finr y los bancos Mundial, regionales y subregionales de desarrollo. La participación conjunta de los bancos privados y los organismos multilaterales en operaciones de cofinanciamiento de proyectos de desarrollo $y$ de ajuste de balanza de pa-

${ }^{2 x} \mathrm{Al}$ respecto ver las declaraciones que formuló recientemente el Director del Fondo Monetario Internacional, Sr. Jacques Larosiére, a la revista "Finanzas y Desarrollo", Ref. 5.

${ }^{-1}$... Ver página 384 del presente trabajo. 
gos (con el FMI) también deberá ser ampliada y perfeccionada. La mayor participación relativa de los organismos multilaterales de financiamiento externo contribuirá, así, a disminuir la carga excesiva que ha pesado sobre los bancos privados en el reciente mecanis. mo de reciclaje.

Así como los componentes del mecanismo deberán ser rediseñados y fortalecidos, también creemos que aquel no podrá funcionar correctamente sino en el contexto de una economía internacional en proceso de ajuste, en el cual el proteccionismo comercial debe ser combatido.

Una de las lecciones que nos ha dejado la crisis contemporánea es que el mundo de la postguerra se ha vuelto funcionalmente interdependiente. Perturbaciones como alzas sucesivas del precio del petróleo por parte de los países de la OPEP, o de alzas de las tasas de interés, la adopción de políticas económicas fuertemente restrictivas, o el aumento del proteccionismo por parte de los países de la $\mathrm{OCDE}$, son capaces de desencadenar procesos de desajuste comercial y financiero de alcance internacional que acaban por limitar severamente la capacidad de pagos y reducir las perspectivas de estabilidad, intercambio comercial y desarrollo de los demás países.

Nuestra tesis es que en el umbral del siglo xxi existe un vasto margen para la cooperación internacional. Se requiere intensificar los esfuerzos de comprensión mutua, de diálogo y de colaboración entre los países industrializados y los países en vías de desarrollo, entre los países exportadores y los importadores de petróleo, entre las organizaciones multilaterales de financiamiento y las fuentes privadas de capital. Nos asiste la convicción de que los intereses económicos que están en juego no son mutuamente excluyentes y que pueden llegar a ser complementarios en el marco de una serie de acciones conjugadas que es necesario iniciar sin demoras.

\section{REFERENCIAS}

1. FMI, Boletin, abril 12, 1982.

2. Jorge Espinoza Carranza, "Las tendencias económicas y financieras internacionales y de América Latina", documento presentado al Primer Foro del Banco de los Trabajadores de Venezuela, c. A., Caracas, 20 de mayo, 1982.

3. FMI, Annual Report 19S1, Table 11, e informes anteriores.

4. Business Week, September 6. 1982, Worry at the World's Banks".

5. "Finanzas y Desarrollo", publicación đel Fim y del BIRF, junio, 1982.
6. Institut Français de Relations Internationales, Ramses 1981, "Coopération ou guerre économique", Rapport annuel de L'Institut, 1981 .

7. Banco Interamericano de Desarrollo, "El papel del Banco en América Latina en la Década de 1980", abril, 1981.

8. OEGD Development Centre, "Conference on borrowing by developing countries on the eurocurrency markets", Summary record, Paris, 21-23 July, 1976. 